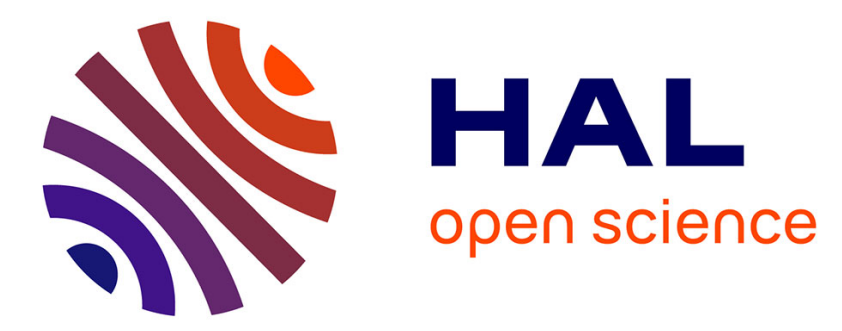

\title{
Evidence of minority carrier traps contribution in deep level transient spectroscopy measurement in $\mathbf{n}-\mathrm{GaN}$ Schottky diode
}

Sarrah Amor, Ali Ahaitouf, Abdelaziz Ahaitouf, Jean-Paul Salvestrini, Abdallah Ougazzaden

\section{To cite this version:}

Sarrah Amor, Ali Ahaitouf, Abdelaziz Ahaitouf, Jean-Paul Salvestrini, Abdallah Ougazzaden. Evidence of minority carrier traps contribution in deep level transient spectroscopy measurement in $\mathrm{n}-\mathrm{GaN}$ Schottky diode. Superlattices and Microstructures, 2017, 101, pp.529-536. 10.1016/j.spmi.2016.11.011 . hal-01830928

\section{HAL Id: hal-01830928 \\ https://hal.science/hal-01830928}

Submitted on 19 Jan 2022

HAL is a multi-disciplinary open access archive for the deposit and dissemination of scientific research documents, whether they are published or not. The documents may come from teaching and research institutions in France or abroad, or from public or private research centers.
L'archive ouverte pluridisciplinaire HAL, est destinée au dépôt et à la diffusion de documents scientifiques de niveau recherche, publiés ou non, émanant des établissements d'enseignement et de recherche français ou étrangers, des laboratoires publics ou privés.

\section{()ㅜ(1)}

Distributed under a Creative Commons Attribution - NonCommercial| 4.0 International 


\title{
Evidence of minority carrier traps contribution in deep level transient spectroscopy measurement in $n-G a N$ Schottky diode
}

\author{
S. Amor, A. Ahaitouf, Az. Ahaitouf, J.P. Salvestrini, A. Ougazzaden \\ Georgia Tech Lorraine and CNRS UMI2958, 57070, Metz, France \\ ${ }^{a}$ Université Sidi Mohammed Ben Abdellah, FST, LERSI, B.P. 2202, Fes, Morocco \\ ${ }^{b}$ Université de Lorraine and CentraleSupélec, LMOPS EA 4423, 2 rue E. Belin 57070, \\ Metz, France \\ ${ }^{c}$ Université Sidi Mohammed Ben Abdellah, FST, LERSI, B.P. 2202, Fes, Morocco \\ ${ }^{d}$ Université de Lorraine and CentraleSupélec, LMOPS EA 4423, 2 rue E. Belin 57070, \\ Metz, France \\ ${ }^{e}$ Université Sidi Mohammed Ben Abdellah, FP Taza, LSI, B.P. 1223, Taza Morocco \\ ${ }^{f}$ Université de Lorraine and CentraleSupélec, LMOPS EA 4423, 2 rue E. Belin 57070 , \\ Metz, France \\ ${ }^{g}$ Georgia Tech Lorraine and CNRS UMI2958, 57070, Metz, France
}

\begin{abstract}
It is shown that deep level transient spectroscopy can be carried out on Schottky diodes to investigate, in addition to majority carrier traps, minority carrier traps. This is possible thanks to the application of a large reverse bias to the device which allows minority carrier injection by lowering their corresponding effective Schottky barrier height. Indeed, when increasing the reverse bias voltage, the deep level transient spectroscopy signal, initially negative and thus showing only majority carrier traps signature, becomes positive, revealing minority carrier traps involvement. A careful analysis of the recorded spectra leads to the identification of four minority carrier traps which have been so far only evidenced using dedicated technique such as minority carrier transient spectroscopy.
\end{abstract}

Keywords: elsarticle.cls, $\mathrm{HT}_{\mathrm{EX}}$, Elsevier, template

2010 MSC: 00-01, 99-00

\footnotetext{
*Corresponding author

Email address: jean-paul.salvestrini@univ-lorraine.fr (J.P. Salvestrini)
} 


\section{Introduction}

III-nitrides semiconductor materials (B, In, Al, Ga) N and their ternary and quaternary alloys are widely studied thanks to their potential use for electronic [1], high power electronic 2], and optoelectronic devices such as photodetectors 5 [3], gas sensors [4] and solar cells [5]. However, defects in semiconductor materials highly influence the transport mechanism and often limit the efficiency of these devices. Thus, the study of these defects and their role in the performance of a given device is an important step in the improvement of material quality and then device efficiency [6]. In this frame, deep level transient spectroscopy (DLTS) is a useful and powerful technique for carrier trap detection and characterization. Various DLTS studies on bulk GaN material were performed on both Schottky diodes, p-n or p-i-n junctions, and several band-gap localized traps have been shown in both n-type and p-type GaN films obtained using different growth techniques including metal organic vapor phase epitaxy ${ }_{15}$ (MOVPE) [7, 8, 9, 10, metal organic chemical vapor deposition (MOCVD) [11, 12, hybride vapor phase epitaxy (HVPE) [13, 14, 15, and molecular beam epitaxy (MBE) [16, 6]. In a recent review paper, Polyakov and Lee [17] inventoried fifteen electron trap levels and seven hole trap levels. From this analysis, it appears that electron trap levels $\mathrm{ET}_{5}, \mathrm{ET}_{10}$ and $\mathrm{ET}_{11}$ and hole trap level $\mathrm{HT}_{4}$ are the most reported and this independently of the growth technique. The electron traps are studied using DLTS whereas hole traps are usually investigated using minority carrier trap spectroscopy (MCTS) [11, 12, 18] or optical deep level transient spectroscopy (ODLTS) to boost the minority carrier concentration [14, 13].

In this work, we report on the direct investigation, using only DLTS, of both minority and majority carriers traps in Schottky diodes realized on GaN epitaxial layers grown by metal organic vapor phase epitaxy (MOVPE). To investigate the minority carrier traps, we exploit the lowering of the effective Schottky barrier for minority carriers under large reverse bias, that allows the injection of holes in the Schottky diode [22]. We then show that, under certain 
bias conditions, this technique can be used to characterize both majority and minority carriers. A deep stepped analysis of the DLTS spectra is performed starting with the clear evidence of minority traps involvement. Then, a careful assignment of the trap levels taking into account of the type of trap (bulk or interface, single point like or linear) is done. Finally, a rigorous fit of the spectra, using a least square fitting procedure, is performed to determine the trap energies and their capture cross sections. The corresponding values are compared with those obtained via Arrhenius plots.

\section{Sample preparation}

$400 \mathrm{~nm}$ thick n-doped GaN, with a targeted doping concentration of $\mathrm{N}_{D}=$ $3 \times 10^{18} \mathrm{~cm}^{-3}$, has been grown by MOVPE on a $3.5 \mu \mathrm{m}$ thick semi-insulating GaN template on sapphire substrates. Before metallization, the samples were cleaned in acetone and etched in HCL ( $3 \mathrm{~mol} / \mathrm{l})$ solution during $5 \mathrm{mn}$ to remove the native oxide. For ohmic contact, $\mathrm{Ti} / \mathrm{Al} / \mathrm{Ti} / \mathrm{Au}$ layers, with thicknesses 45 of $15,200,15,200 \mathrm{~nm}$, respectively, were deposited by thermal evaporation and then annealed at $500 \mathrm{C}$ for $15 \mathrm{mn}$ in a flowing $\mathrm{N}_{2}$ atmosphere. To form Schottky contacts, circular dots of $200 \mu \mathrm{m}$ diameter were fabricated on the cleaned surface using photolithography technique and deposition of $150 \mathrm{~nm}$ thick Pt layer using an e-beam evaporation system. Current-voltage and capacitancevoltage measurements were carried out using a Keithley Source Measure Unit 4200 SCS, and DLTS measurements were performed using a Semilab DLS 83 D setup.

\section{Results and discussion}

Current- and capacitance-voltage measurements were first performed on the fabricated diodes. From the collected data, values of the ideality factor n, Schottky barrier height $\Phi_{b}$, series resistance $R_{s}$, and doping concentration $\mathrm{N}_{D}$ can be derived 24] and are listed in table 1. These values, as well as current voltage plots, indicate that very good Schottky diodes were achieved. 
Table 1: Typical values of the ideality factor $\mathrm{n}$, Schottky barrier height $\Phi_{b}$, series resistance $R_{s}$, and doping concentration $\mathrm{N}_{D}$ as deduced from current- and capacitance-voltage measurements.

\begin{tabular}{c||c|c|c|c|c}
\multirow{2}{*}{\multicolumn{1}{c||}{ Parameters }} & \multicolumn{3}{c|}{$\mathrm{I}-\mathrm{V}$ measurements } & \multicolumn{2}{c}{ C-V measurements } \\
\cline { 2 - 6 } & $\mathrm{n}$ & $\Phi_{b}(\mathrm{eV})$ & $\mathrm{R}_{s}(\Omega)$ & $\mathrm{N}_{D}\left(\mathrm{~cm}^{-3}\right)$ & $\Phi_{b}(\mathrm{eV})$ \\
\hline \hline Measured values & 1.3 & 1.01 & 107.1 & $3.17 \times 10^{18}$ & 1
\end{tabular}

\subsection{Evidence of minority carrier traps signature in the DLTS signal}

Figure 1(a) shows typical DLTS spectra recorded on a fabricated Schottky diode for reverse bias voltages $\mathrm{U}_{r}$ ranging from $-0.75 \mathrm{~V}$ to $-2 \mathrm{~V}$, a voltage pulse amplitude $\mathrm{U}_{p}=1 \mathrm{~V}$, and a frequency of $23 \mathrm{~Hz}$. For $\mathrm{U}_{r}=-0.75 \mathrm{~V}$, the DLTS

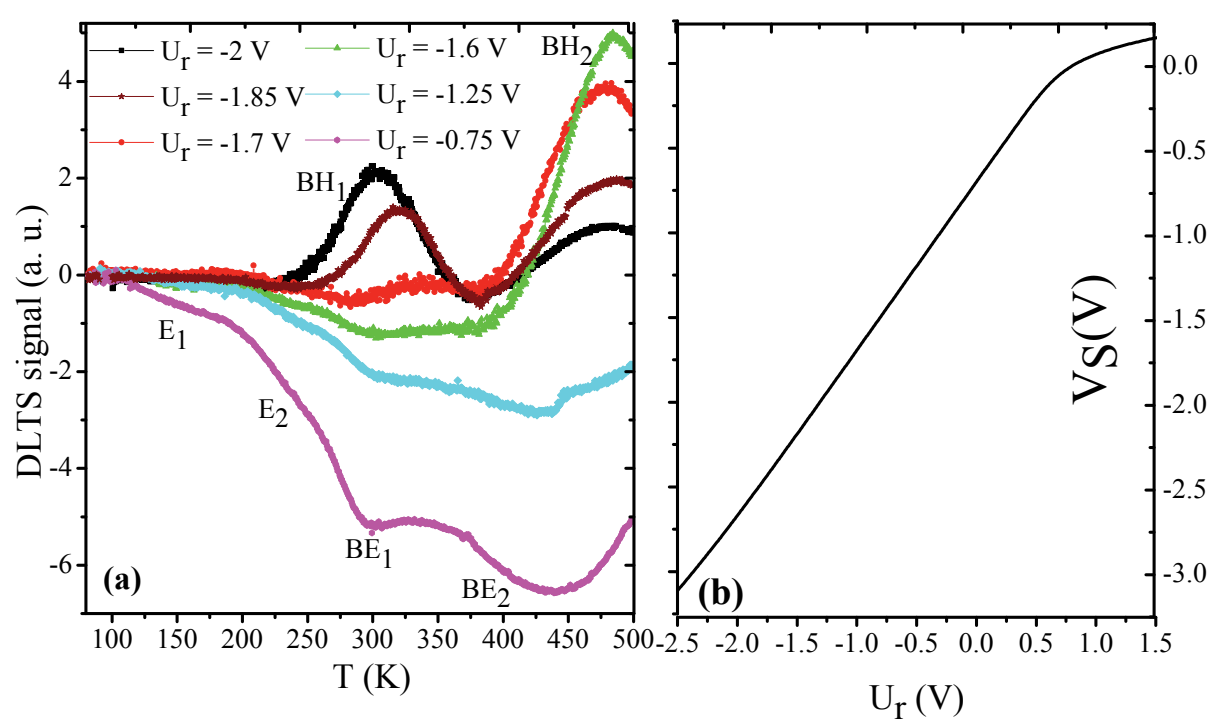

Figure 1: a) Typical DLTS spectra recorded on a Schottky diode for reverse bias voltages $\mathrm{U}_{r}$ ranging from $-0.75 \mathrm{~V}$ to $-2 \mathrm{~V}$, a voltage pulse amplitude $\mathrm{U}_{p}=1 \mathrm{~V}$ and a frequency of $23 \mathrm{~Hz}$ and b) surface potential of the semiconductor as deduced from current-voltage measurements.

signal is negative and the different peaks $\mathrm{E}_{1}$ and $\mathrm{E}_{2}$ and broad bands $\mathrm{BE}_{1}$ and $\mathrm{BE}_{2}$ that can be seen correspond to majority carrier trap levels response. With 

at $\mathrm{U}_{r}=-1.6 \mathrm{~V}$, a first positive peak appears. For further increase of the reverse bias voltage, the DLTS signal becomes fully positive and two broad peaks $\mathrm{BH}_{1}$ and $\mathrm{BH}_{2}$ corresponding to minority carrier traps can be observed. It is to be noticed that the amplitude of the peak appearing at around $475 \mathrm{~K}$ decreases which appears at around $325 \mathrm{~K}$ increases. The revelation of minority carrier traps only by DLTS must be considered carefully to avoid any spurious origin of the positive peaks, such as series resistance effect on the DLTS signal. In the case of small series resistance, the surface potential of a Schottky diode is only given by the difference between the applied voltage and built-in potential, and thus a monotonic variation of the surface potential with the applied voltage is expected. This is no longer the case for high series resistance [24, 25]. An increase of the applied voltage can lead to a decrease of the surface potential, and thus to an opposite variation of the capacitance measured by DLTS. Calculation done according to the work of Grillot et al. 23. leads to $530 \Omega$, as a value of the series resistance required to have such a behavior in our devices which is five times larger than the measured one. Moreover, as shown in Fig. 1(b), the surface potential, as derived from current voltage measurements [24, 25], exhibits a fully monotonic behavior with the applied voltage, clearly indicating no possible opposite variation of the capacitance under voltage application.

Minority carrier signatures in the DLTS spectra recorded for large applied reverse voltage can be explained by a minority carrier injection originating in the lowering of the effective Schottky barrier for holes as shown in Fig. 2, Indeed, the effective Schottky barrier heights $\Phi_{b n}^{e f f}$ and $\Phi_{b p}^{e f f}$ for electrons and holes, respectively, become:

$$
\left\{\begin{array}{l}
\Phi_{b n}^{e f f}=\Phi_{b}-q U_{r} \\
\Phi_{b p}^{e f f}=E g-\Phi_{b}+q U_{r}
\end{array}\right.
$$

where $\Phi_{b}$ is the Schottky barrier height as deduced from the current voltage measurements (see table 1). The electrons and holes current density under 


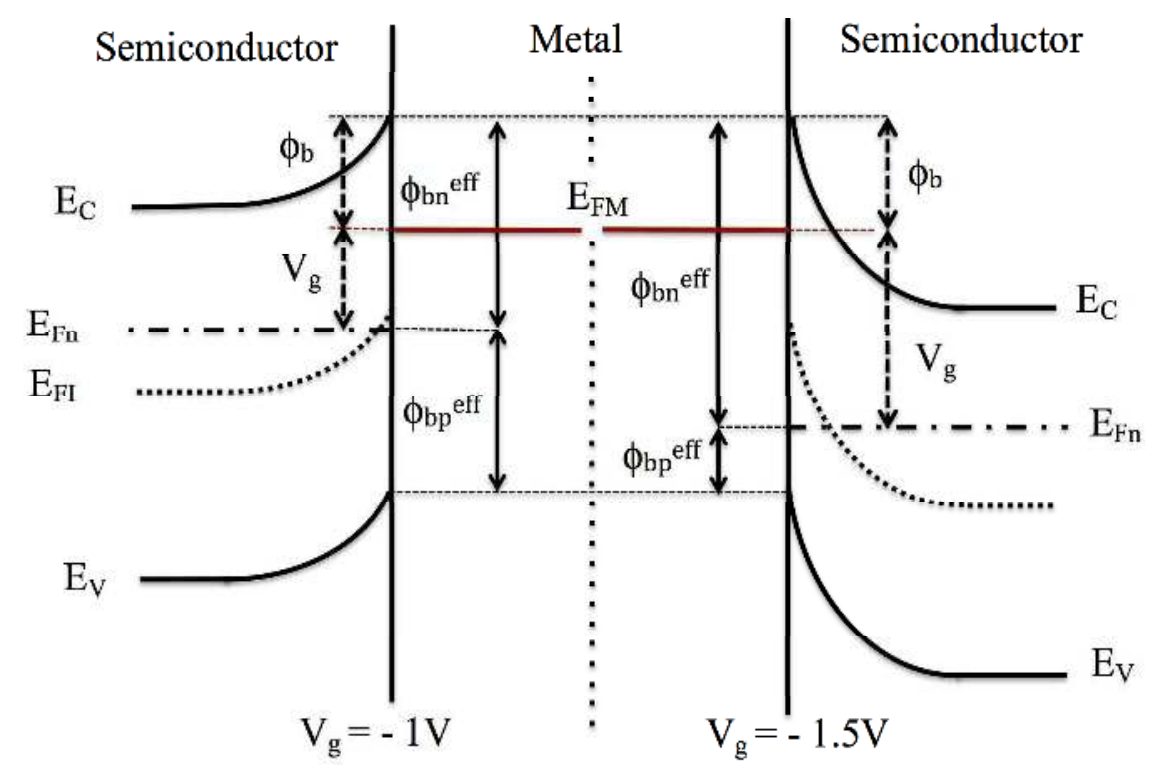

Figure 2: Band diagram of a reverse biased Schottky structure showing the variation of the effective barrier height for electrons and holes for two different reverse bias voltage.

reverse bias polarization can be described by:

$$
\left\{\begin{array}{l}
J_{n}=A_{n}^{*} T^{2} \exp \left(-\frac{q \Phi_{b n}^{e f f}}{k T}\right)\left[1-\exp \left(-\frac{q U_{r}}{k T}\right)\right] \\
J_{p}=A_{p}^{*} T^{2} \exp \left(-\frac{q \Phi_{b p}^{e f f}}{k T}\right)\left[1-\exp \left(-\frac{q U_{r}}{k T}\right)\right]
\end{array}\right.
$$

where $\mathrm{A}_{n}^{*}=26.4 \times 10^{4} \mathrm{~A} / \mathrm{K}^{2} / \mathrm{m}^{2}$ and $\mathrm{A}_{p}^{*}=96.1 \times 10^{4} \mathrm{~A} / \mathrm{K}^{2} / \mathrm{m}^{2}$ are the respective effective Richardson constant for electrons and holes in GaN material. Figure 3 shows the simulated, using equations 1 and 2 , and measured reverse current density-voltage curves for a GaN Schottky diode. It can be seen that in both curves, beyond a reverse voltage greater than $1.6 \mathrm{~V}$, the minority carrier current density $\mathrm{J}_{p}$ becomes dominant allowing minority carriers to flow in the depletion region and be captured by the corresponding carrier traps, confirming the minority carrier injection in our device. It is to be noticed that, compared to the the simulated current density, the contribution of the minority carrier to the current density is higher while the minority carrier injection is less pronounced, likely due to carrier recombinations and/or trapping via interface states. 

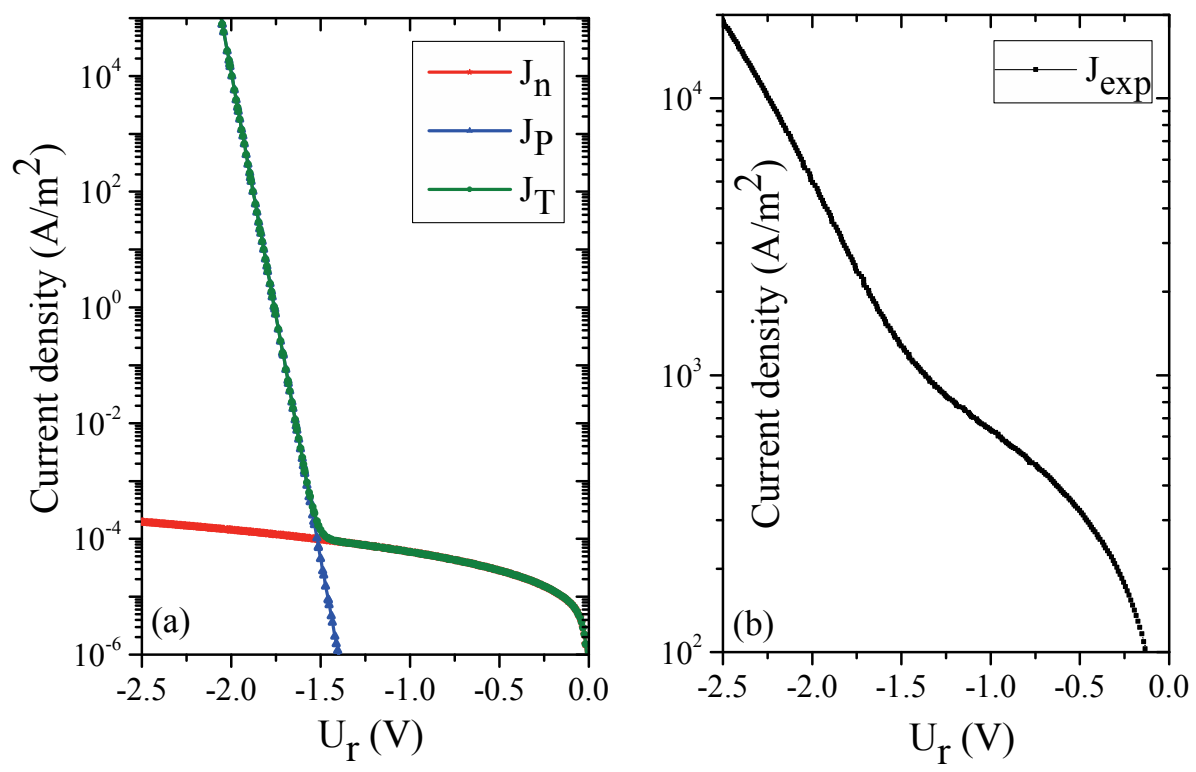

Figure 3: (a) Theoretical and (b) measured reverse current density-voltage curves in a GaN Schottky diode

\section{Trap assignment}

To characterize the different trap levels, DLTS spectra are generally analyzed by plotting, for each trap and thus peak obtained for different frequencies of the probe signal, the emission rate versus the inverse of the temperature. From the corresponding Arrhenius plot, both the trap activation energy $\mathrm{E}_{a}$ and capture cross section $\sigma$ can be derived. This can be done quite easily if only one type of trap contribute to the DLTS spectrum. In the present case, this is more difficult, since both majority and minority carrier traps contribute in DLTS spectra, especially for intermediate applied reverse bias as shown on Fig. 1(a). It is clear that depending on the applied reverse bias, because some peaks appear at close temperatures, majority carrier trap signatures can hide those of minority carrier and reversely, leading to errors in the determination of the traps characteristics. We first did a careful analysis of the peaks nature before final assignment of the different peaks appearing in the different DLTS spectra (different reverse bias 
and frequencies).

\subsection{Bulk or interface traps}

Figure 4 shows the DLTS spectra recorded for several pulse amplitudes and for $\mathrm{U}_{r}=-0.75 \mathrm{~V}$ (Fig. 4(a)) and $\mathrm{U}_{r}=-2 \mathrm{~V}$ (Fig. 4(b)). We can see that
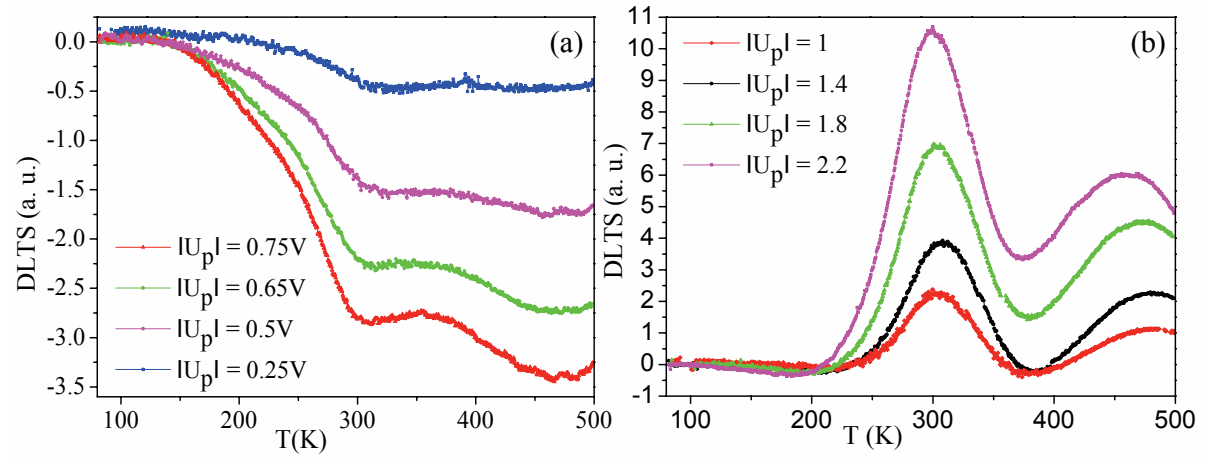

Figure 4: DLTS spectra recorded for several pulse amplitudes and for (a) $\mathrm{U}_{r}=-0.75 \mathrm{~V}$ and (b) $\mathrm{U}_{r}=-2 \mathrm{~V}$.

for $\mathrm{U}_{r}=-0.75 \mathrm{~V}$ (Fig. 4(a)) all the peaks (assigned to majority carrier traps) remain unchanged in both position and shape. For $\mathrm{U}_{r}=-2 \mathrm{~V}$ (Fig. 4(b)), the same behavior can be observed for the the peak around $300 \mathrm{~K}$ assigned to $\mathrm{BH}_{1}$ minority carrier trap whereas the second peak around $475 \mathrm{~K}$ and assigned to $\mathrm{BH}_{2}$ minority carrier trap moves toward small temperature when $\mathrm{U}_{p}$ is increased. Moreover, as seen on Fig. 1 its amplitude decreases when $U_{r}$ increases. Thus, according to the analysis of Yamasaki et al. [26, all the peaks can be considered as corresponding to bulk traps except the $\mathrm{BH}_{2}$ peak which could correspond to an interface trap.

\subsection{Single point like or linear defect}

Figure 5 shows the logarithmic dependence of the DLTS peak amplitude as function of the pulse duration $\tau_{p}$. A rather linear dependence of the amplitude with $\tau_{p}$ is obtained for the majority carrier traps $\mathrm{E}_{1}$ and $\mathrm{E}_{2}$, whereas a non linear dependence can be seen for the other traps. According to the work of 

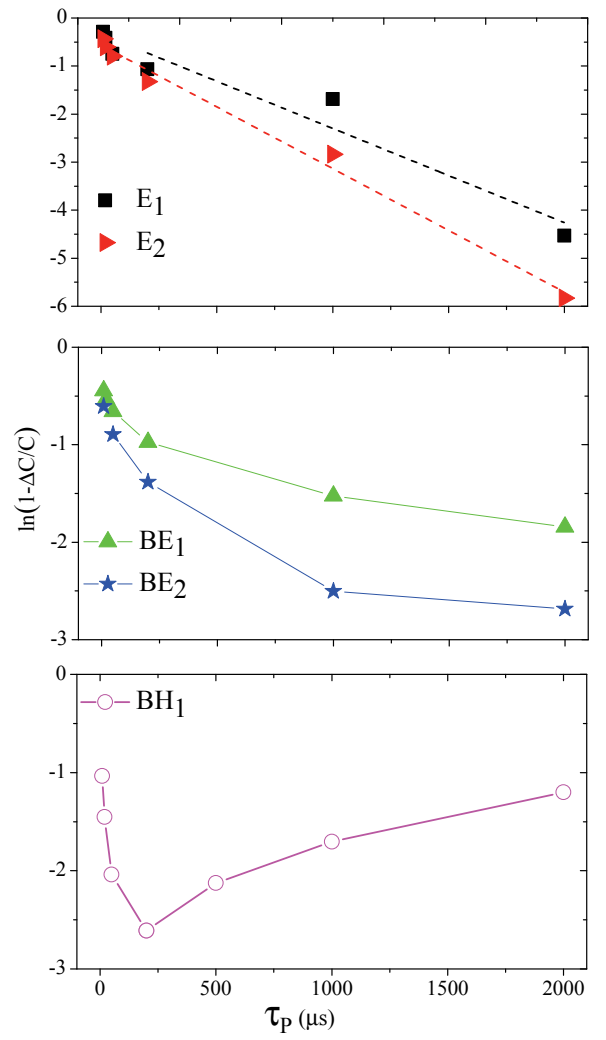

Figure 5: Plot of $\operatorname{Ln}\left(1-\frac{\Delta C}{\Delta C_{\infty}}\right)$ versus the pulse duration for $\mathrm{U}_{r}=-0.75 \mathrm{~V}, \mathrm{U}_{p}=2.2 \mathrm{~V}, \mathrm{f}$ $=23 \mathrm{~Hz}\left(\mathrm{E}_{1}, \mathrm{E}_{2}, \mathrm{BE}_{1}, \mathrm{BE}_{2}\right)$ and $\mathrm{U}_{r}=-2 \mathrm{~V}, \mathrm{U}_{p}=2.2 \mathrm{~V}, \mathrm{f}=23 \mathrm{~Hz}\left(\mathrm{BH}_{1}\right)$.

Venturi et al. [27, the majority carrier traps $\mathrm{E}_{1}$ and $\mathrm{E}_{2}$ can thus be considered as single point like defects while the broad bands $\mathrm{BE}_{1}, \mathrm{BE}_{2}$ and $\mathrm{BH}_{1}$ can be considered as distributed trap levels.

\subsection{Theoretical simulation and fitting results}

The temperature dependence of the DLTS signal for either a single electron or hole trap can be expressed by [28, 29]:

$$
\frac{\Delta C}{C_{o}}=\frac{ \pm N_{T}}{2 \times N_{A, D} \times e_{n, p} \times T_{m}}\left[1-\exp \left(-\frac{e_{n, p} \times T_{m}}{2}\right)\right]^{2}
$$

where $\mathrm{C}_{o}$ is the sample capacitance at the voltage $\mathrm{U}_{r}, \mathrm{~N}_{T}$ the trap density, $\mathrm{T}_{m}$ the inverse of the measurement frequency, $\mathrm{N}_{A, D}$ the doping concentration, $\mathrm{e}_{n, p}$ 
the electron (hole) emission rate, given by:

$$
e_{n, p}=\sigma_{n, p} \times v_{n, p} \times N_{C, V} \times \exp -\left(\frac{E_{a}}{k T}\right)
$$

$\mathrm{N}_{C, V}$ is the effective density of states in the conduction or valence band, $\sigma_{n, p}$ the capture cross section of the trap for electrons or holes, $v_{n, p}$ the average thermal velocity of electrons (holes), k the Boltzmann constant, and $E_{a}$ the trap activation energy. Using equation 3 to describe each peak of a DLTS spectrum, it is thus possible to build the full mathematical description of the spectrum. This model is then used to fit the corresponding experimental DLTS spectrum using a least square technique. The trap activation energy, the capture cross section and the trap density are considered as fitting parameters. All the experimental spectra obtained for different $\mathrm{U}_{R}, \mathrm{U} p$, and frequency, have been fitted taking into account of several trap assignment possibilities for the broad bands observed in the case of distributed trap levels, as discussed just above. The crossed comparison of all the fits renders the procedure robust and trustable. That is why, as shown in Fig. 6, after the assessment of a large number of possible fit results, we propose to decompose the broad peaks $\mathrm{BE}_{1}$ and $\mathrm{BE}_{2}$ into two electrons trap levels each, labeled $\mathrm{E}_{3}, \mathrm{E}_{4}, \mathrm{E}_{5}$ and $\mathrm{E}_{6}$. The same approach has been used for the broad peak $\mathrm{BH}_{1}$ which is decomposed into three hole bulk trap levels labeled $\mathrm{H}_{1}, \mathrm{H}_{2}$ and $\mathrm{H}_{3}$. Finally, the full analysis procedure brings out the existence of six electrons bulk traps labelled $E_{1}-E_{6}$, three bulk hole traps $H_{1}-H_{3}$ and an interface trap $\left(\mathrm{BH}_{2}\right)$. Their corresponding characteristics are gathered in table2. They are compared to those obtained via the classical analysis in terms of Arrhenius plots $e_{n} / T^{2}$ versus $1 / T$ which allows the derivation of the activation energy from the slope and the capture cross section from the intercept at $T^{-1}=0$. A typical example of this analysis conducted on spectra measured for $\mathrm{U}_{R}=-2 \mathrm{~V}, \mathrm{U}_{p}=1 \mathrm{~V}, \mathrm{Tp}=500 \mu \mathrm{s}$ and frequencies of $1 \mathrm{~Hz}, 6 \mathrm{~Hz}$, $11 \mathrm{~Hz}$, and $35 \mathrm{~Hz}$ is shown on figure 7

As shown in table 2, there is a rather good matching between values of trap activation energy and capture cross section obtained by either the fit procedure or Arrhenius plot analysis. Values reported in table 2 are also in good agreement 

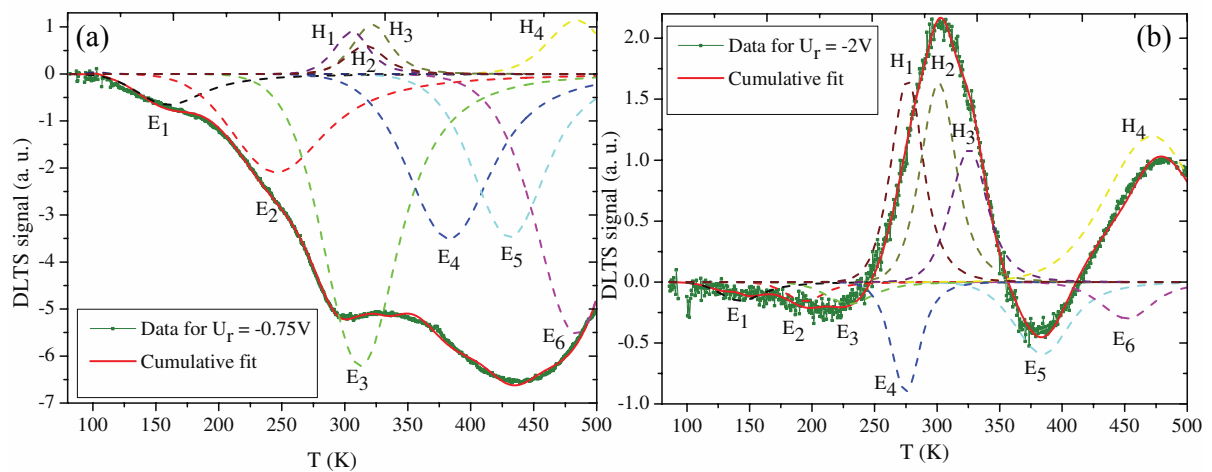

Figure 6: Assignment of the trap by decomposition of the (a) broad peaks $\mathrm{BE}_{1}$ and $\mathrm{BE}_{2}$ into two electrons trap level each, labeled $\mathrm{E}_{3}, \mathrm{E}_{4}, \mathrm{E}_{5}$ and $\mathrm{E}_{6}$, (b) broad peak $\mathrm{BH}_{1}$ into three hole bulk trap level labeled $\mathrm{H}_{1}, \mathrm{H}_{2}$ and $\mathrm{H}_{3}$.

Table 2: Activation energies $E_{a}$, capture cross section $\sigma$ and density , $N_{T}$, of the discovered traps in our sample. The $E_{a}$ means respectively $E_{c}-E$ and $E-E_{v}$ for the majority and minority traps. $\mathrm{BH}_{2}$ is an interface trap with $\mathrm{N}_{s s}=9 \times 10^{14} \mathrm{~cm}^{-2} \mathrm{eV}^{-1}$.

\begin{tabular}{c|cc|cc|c} 
Trap & \multicolumn{2}{|c|}{ Fit procedure } & \multicolumn{2}{|c|}{ Arrhenius plot } & Literature [17] \\
\cline { 2 - 6 } label & $\mathrm{E}_{a}(\mathrm{eV})$ & $\sigma_{a}\left(\mathrm{~cm}^{2}\right)$ & $\mathrm{E}_{a}(\mathrm{eV})$ & $\sigma_{a}\left(\mathrm{~cm}^{2}\right)$ & Corresponding trap \\
\hline \hline$E_{1}$ & 0.15 & $1.25 \times 10^{-19}$ & 0.15 & $4.6 \times 10^{-18}$ & $\mathrm{ET}_{2}$ \\
$E_{2}$ & 0.2 & $3.1 \times 10^{-20}$ & 0.23 & $5.2 \times 10^{-20}$ & $\mathrm{ET}_{5}$ \\
$E_{3}$ & 0.3 & $1.8 \times 10^{-19}$ & 0.3 & $6 \times 10^{-20}$ & $\mathrm{ET}_{6}$ \\
$E_{4}$ & 0.5 & $2.6 \times 10^{-18}$ & 0.5 & $2.7 \times 10^{-18}$ & $\mathrm{ET}_{8}$ \\
$E_{5}$ & 0.65 & $1.9 \times 10^{-17}$ & 0.7 & $4.7 \times 10^{-16}$ & $\mathrm{ET}_{11}$ \\
$E_{6}$ & 0.9 & $5.2 \times 10^{-15}$ & 1.1 & $9.4 \times 10^{-14}$ & $\mathrm{ET}_{13}$ \\
$H_{1}$ & 0.6 & $1 \times 10^{-14}$ & 0.57 & $2.6 \times 10^{-14}$ & $\mathrm{HT}_{2}$ \\
$H_{2}$ & 0.64 & $9.3 \times 10^{-14}$ & 0.7 & $8.1 \times 10^{-14}$ & $\mathrm{HT}_{3}$ \\
$H_{3}$ & 0.7 & $4.1 \times 10^{-14}$ & 0.76 & $4.9 \times 10^{-13}$ & $\mathrm{HT}_{4}$ \\
\hline \hline$B H_{2}$ & $\sim 1$ & - & - & & $\mathrm{HT}_{5}$
\end{tabular}

with those reported in the literature and gathered by Polyakov and Lee [17, and corresponding to trap levels found in non irradiated, n-doped, MOCVD 


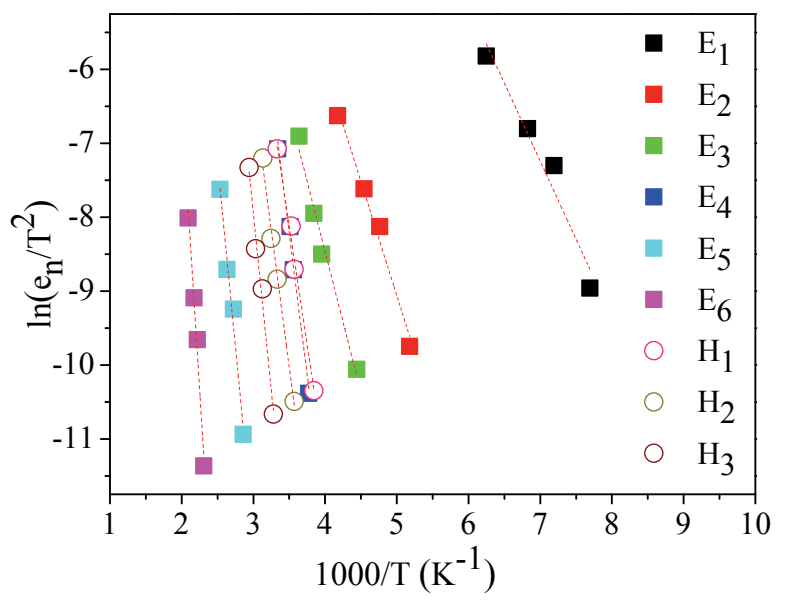

Figure 7: Arrhenius plots for the different electron and hole traps and derived from DLTS measurements recorded in the following conditions: $\mathrm{U}_{R}=-2 \mathrm{~V}, \mathrm{U}_{p}=1 \mathrm{~V}, \mathrm{Tp}=500 \mu \mathrm{s}$ and frequencies of $1 \mathrm{~Hz}, 6 \mathrm{~Hz}, 11 \mathrm{~Hz}$, and $35 \mathrm{~Hz}$

grown GaN-based Schottky diodes. According to this review paper, level $E_{1}$ corresponds to $E T_{2}$ and is probably due to dislocations. $E_{2}$ corresponds to the most commonly reported $E T_{5}$ and is favored by N-rich growth conditions and probably due to nitrogen vacancies or their complexes. $E_{3}$ corresponds to $E T_{6}$ observed in as grown n-GaN films with a high dislocation density, $E_{4}$ to $E T_{8}$ sometimes observed in MOCVD grown undoped n-GaN films, $E_{5}$ to $E T_{11}$ promoted by the N-rich growth conditions and $E_{6}$ to $E T_{13}$ which is also a commonly reported deep trap for $\mathrm{n}-\mathrm{GaN}$ films. For the hole traps, $H_{1}$ corresponds to $H T_{2}$ often observed in n-GaN films, $H_{2}$ to $H T_{3}$ and $H_{3}$ to $H T_{4}$ for which the origin is not well understood so far but definitely includes some native point defects. Finally, $\mathrm{BH}_{2}$ that we consider as an interface trap likely corresponds to the hole trap described as being dominant in various samples and with a complex nature $\left(\mathrm{HT}_{5}\right)$. It is to be noticed that the capture cross section of the hole traps is much more larger that the one of the electron trap. This means that hole traps are much more efficient than electron traps especially as soon as the surface potential in the semiconductor makes the valence band edge much 
closer to the traps level energy, rendering their contribution to the DLTS signal predominant for large applied bias voltage.

\section{Conclusion}

In conclusion, we have shown that deep level transient spectroscopy can be carried out on Schottky diodes to investigate both majority and minority carrier traps on n-doped GaN films grown by metal organic vapor phase epitaxy. This is possible thanks to the application of a large reverse bias to the device which allows minority carrier injection by lowering their corresponding effective Schottky barrier height. A careful analysis of the DLTS spectra leads to the identification of four minority carrier traps and six majority carrier traps, in good agreement with the most reported traps in the literature. The rigorous fitting procedure results are confirmed by the traditional Arrhenius plot.

\section{Acknowledgments}

The authors would like to thank the Ministry of Higher Education, Scientific Research and Professional Training and National Centre of Scientific and Technic Research (CNRST) of Morocco and, the Ministry of Foreign Affairs and National Centre of Scientific Research (CNRS) of France for their financial support under the Volubilis MA/11/253(257) and CNRS-CNRST, SPI08/2013 programs.

\section{References}

[1] M. Shur, R. Gaska, and A. Bykhovski, Sol. Stat. Electron. 43, 14511458 200 (1999)

[2] S. Bouzid-Driad, H. Maher, N. Defrance, V. Hoel, J. C. D. Jaeger, M. Renvoise, and P. Frijlink, Electron. Dev. Lett. 34, 3638 (2013) 
[3] H. Srour, J. P. Salvestrini, A. Ahaitouf, S. Gautier, T. Moudakir, B. Assouar, M. Abarkan, S. Hamady, and A. Ougazzaden, Appl. Phys. Lett. 99, 221101 $2211013(2011)$

[4] C. Bishop, J.-P. Salvestrini, Y. Halfaya, S. Suresh, Y. El Gmili, L. Pradere, J. Y. Marteau, B. Assouar, P.L. Voss, and A. Ougazzaden, Appl. Phys. Lett. 106, $243504(2015)$

[5] M. Arif, J.P. Salvestrini, J. Streque, M.B. Jordan, Y. El Gmili, S. Sundaram, X. Li, G. Patriarche, P.L. Voss, and A. Ougazzaden, Appl. Phys. Lett. 109, 133507 (2016)

[6] C.D.Wang, L.S.Yu, S.S.Lau, E.T.Yu, W.Kim, A.E. Botchkarev, and H. Morkoc, Appl. Phys. Lett. 72, 12111213 (1998)

[7] W. Götz, N. M. Johnson, H. Amano, and I. Akasaki, App. Phys. Lett. 65, 463465 (1994)

[8] W. I. Lee, T. C. Huang, J. D. Guo, and M. S. Feng, App. Phys. Lett. 67, $17211723(1995)$

[9] P. Hacke, T. Detchprohm, K. Hiramatsu, N. Sawaki, K. Tadatomo, and K. Miyake, J. App. Phy. 76, 304309 (1994)

${ }_{220}^{20}$ [10] D. Haase, M. Schmid, W. Kürner, A. Dörnen, V. Härle, F. Scholz, M. Burkard, and H. Schweizer, App. Phys. Lett. 69, 25252527 (1996)

[11] Y. Tokuda, Y. Yamada, T. Shibata, S. Yamaguchi, H. Ueda, T. Uesugi, and T. Kachi, phys. status solidi C 8, 22392241 (2011)

[12] Y. Tokuda, CS MANTECH Conference, May 19-22, 2014, Denver, Col225 orado, USA

[13] A. Polyakov, N. Smirnov, E. Yakimov, A. Usikov, H. Helava, K. Shcherbachev, A. Govorkov, Y. N. Makarov, and I.-H. Lee, J. Alloy. Compd. 617, $200206(2014)$ 
[14] I.-H. Lee, A. Y. Polyakov, N. B. Smirnov, A. V. Govorkov, A. S. Usikov, H. Helava, Y. N. Makarov, and S. J. Pearton, J. Appl. Phys. 115, 223702 (2014)

[15] T. T. Duc, G. Pozina, E. Janzn, and Carl Hemmingsson, J. Appl. Phys. 114, $153702(2013)$,

[16] Z-Q. Fang, D. C. Look, W. Kim, Z. Fan, A. Botchkarev, and H. Morkoc, Applied Physics Letters 72, 22772279(1998)

[17] A. Y. Polyakov and I.-H. Lee, Mater. Sci. Eng. : R : Rep. 94, 156 (2015)

[18] P. Muret, A. Philippe, E. Monroy, E. Muoz, B. Beaumont, F. Omns, and P. Gibart, J. Appl. Phys. 91, 29983001 (2002)

[19] F. D. Auret and M. Nel, J. Appl. Phys., 61, 25462549 (1987)

[20] J. W. Kim, G. H.Song and J. W. Lee, App. Phys. Lett., 88, 182103 (2006)

[21] Y. Tokuda, Y. Matsuoka, H. Ueda, O. Ishiguro, N. Soejima and T. Kachi, Materials Science Forum, 600-603, 1297-1300 (2009).

[22] M. J. Malachowski and J. Stepniewski, Sol. Stat. Electron. 24, 381385 (1981)

[23] P. N. Grillot, S. A. Ringel, E. A. Fitzgerald, G. P. Watson, and Y. H. Xie, J. Appl. Phys. 77, 676685 (1995)

[24] A. Ahaitouf, H. Srour, S. O. S. Hamady, N. Fressengeas, A. Ougazzaden, and J.P. Salvestrini, Thin Solid Films 522, 345351 (2012).

[25] A. Ahaitouf, A. Ahaitouf, J. P. Salvestrini, and H. Srour, J. Semicond. 32, $104002(2011)$

[26] K. Yamasaki, M. Yoshida, and T. Sugano, Jpn. J. Appl. Phys. 18, 113 (1979)

[27] G. Venturi, A. Castaldini, A. Cavallini, M. Meneghini, E. Zanoni, D. Zhu, and C. Humphreys, Appl. Phys. Lett. 104, 211102 (2014) 
[28] D.V. Lang, J. App. Phys. 45, 3023-3030 (1974)

[29] G. Couturier, A. Thabti, A.S. Barrière, Revue de Physique Appliquée, 24, 243-249 (1989). 